\title{
Agency modulates interactions with automation technologies
}

\author{
Kevin Le Goff ${ }^{1}$, Arnaud Rey ${ }^{2}$, Patrick Haggard ${ }^{3}$, Olivier Oullier ${ }^{2}, \&$ Bruno Berberian $^{1 *}$ \\ 1. Systems Control and Flight Dynamics Department, \\ ONERA, Salon de Provence, France \\ kevin.le_goff@onera.fr \\ bruno.berberian@onera.fr \\ 2. Laboratoire de Psychologie Cognitive - CNRS \\ Aix-Marseille University, Marseille, France \\ arnaud.rey@univ-amu.fr \\ olivier.oullier@univ-amu.fr \\ 3. Institute of Cognitive Neuroscience \\ University College London, United Kingdom \\ p.haggard@ucl.ac.uk
}

Exact word count of text: ??? words (abstract and main text)

Disclosure statement: The authors declare no conflict of interest.

Acknowledgments: We thank the 'Direction Générale de l'Armement' (DGA) for its financial support to the first author and Arnd Rose (SensoMotoric Instruments) for his technical assistance with the eyetracking technology. This work has been supported by a grant from ANR/FRAE (Young researcher program - ANR-15-CE26-0010-01).

* Corresponding author:

Bruno Berberian

Information Processing and Systems Department

ONERA

Centre de Salon de Provence

Base Aérienne 701

13661 Salon Air - France

E-mail: bruno.berberian@onera.fr 


\begin{abstract}
:
The increasing presence of automation between operators and automated systems tends to disrupt operators from action outcomes, leading them to leave the control loop. The theoretical framework of agency suggests that priming the operator about the system's upcoming behaviour could help restore an appropriate sense of control and increase user acceptability of what the system is doing. In a series of two experiments, we test whether providing information about what the system is about to do next leads to an increase in the level of user acceptability, concomitant with an increase in control and performance. Using an aircraft supervision task, we demonstrated the benefit of prime messages regarding system acceptance and performance. Taken together, our results indicate that the principles proposed by this framework could be used to improve human-machine interaction and maintain a high level of sense of control in supervisory tasks.
\end{abstract}

Keywords: Agency; User acceptability; Performance; Human-machine interaction;

Perception-Action cycle; Eye-tracking

Practitioner Summary:

The out-of-the-loop performance problem is a major potential consequence of automation, leaving operators helpless to takeover automation in case of failure. Using an aircraft supervision task, the following article illustrates how the psychological approach of agency can help improving humansystem interactions by designing more acceptable and more controllable automated interfaces 


\section{Introduction}

The term 'sense of agency' refers to the experience of controlling one's own actions, and, through them, events in the outside world (Chambon and Haggard 2012). The sense of agency proper may itself be subdivided into a sense of intentionality or intentional causation, a sense of initiation and a sense of control (Pacherie 2008). In the present paper, we focused on the latter dimension of agency, the sense of control, as it appears to be an essential aspect in human-machine interactions.

\section{Sense of agency in socio-technical systems}

Recently, the concept of agency has been applied to the Human Computer Interaction (HCI) domain (Berberian et al. 2012, 2013; Limerick, Coyle, and Moore 2014, 2015; McEneaney 2009, 2013; Obhi and Hall 2011). During the interactions with technology, it has been shown that the simple process of producing an action to cause an intended outcome depends upon several variables that can alter the agentive experience dramatically (Limerick, Coyle, and Moore 2014). For example, in aviation domain, Berberian et al. (2012) investigated the participants' sense of agency when performing an aircraft supervision task using a flight simulator under different levels of automation. The task required the participant to observe a flight plan and after a random time interval, a conflict occurred due to the presence of another plane. The participant was required to decide an appropriate command and implement it using a button-based interface. In accordance with an established classification (Sheridan \& Verplank, 1978), there were varying levels of automation of the task, from the user having complete control (no automation) to the computer executing the entire task with the participant simply observing (full automation). Berberian et al. (2012) found a decrease in agency (for both implicit and explicit measures) concomitant with the increase in automation. They argued that the increasing level of automation tends to distract operators from action outcomes, decrease their sense of control and therefore disrupt their overall performance.

Further empirical evidence comes from Coyle et al. (2012). In a machine-assisted point-andclick task, these authors explore how the assistance given to participants could have an effect on the user's sense of agency. They showed that, up to a certain point, the computer could assist users while 
also allowing them to maintain a sense of control and ownership of their actions and the outcomes of those actions. However, their results suggested that beyond a certain level of assistance users experienced a detectable loss in their sense of agency. Taken together, these studies indicate that automation technology could disturb the mechanism underlying our sense of agency. This decrease in agency could generate critical concern regarding both automation acceptability and operator behaviour.

The loss of agency: acceptability, involvement and performance issues

Improving acceptability of new technologies by human operators is an important area of concern for equipment suppliers (Horberry, Stevens, and Regan 2014). To be acceptable, new technologies must be reliable, efficient and useful. However, such qualities do not guarantee acceptability from human operators. As pointed out by Shneiderman and Plaisant (2004), users strongly desire the sense that they are in charge of the system and that the system responds to their actions. In that sense, a decrease in the sense of control when dealing with highly automated systems has the potential to seriously threaten the system's acceptability. This echoes Baron (1988) who claimed: "Perhaps the major human factors concern of pilots in regard to introduction of automation is that, in some circumstances, operations with such aids may leave the critical question, who is in control now, the human or the machine?"

In addition to this problem of acceptability, a decrease in the sense of control could also dramatically impact the behaviour of human operators. Particularly, the attribution of responsibility plays an important role; several studies have shown that being involved in the consequence of our actions is a necessary condition to act ethically (Bandura 1999; Bandura et al. 1996; Bratman 2007; Borg et al. 2006). Yet, the sense of agency is known to underpin this concept of responsibility (Haggard 2017); further, the feeling of being an agent seems intimately linked to the experience and allocation of responsibility (Frith 2014; Moretto, Walsh, and Haggard 2011). For example, it has been shown that the decrease in the sense of agency and the related decrease in responsibility attribution lead to an increase in antisocial behaviour (Caspar et al. 2016; Caspar et al. 2017). It indicates that 
people's choice to act ethically or not, that is, to carry out actions that are judged to be 'right' or 'wrong' is shaped by our own beliefs about our involvement in the results of the action (i.e., our sense of agency). The loss of agency might therefore constitute a form of moral disengagement regarding these actions and disturb the mechanism classically used to regulate human behaviour (Bandura 1999).

Finally, this form of disengagement is also known to impact human performance. Particularly, studies investigating error-related potentials (i.e., cerebral activity associated with the monitoring of the consequences of an action; see San Martın 2012 for a review) show a degradation of monitoring associated with a reduction in the sense of agency (Bednark and Franz 2014; Caspar et al. 2016; Kühn et al. 2011; Li et al. 2010, 2011; Timm et al. 2014). In addition, a relationship between sense of control and one's motivation and willingness to make efforts has recently been proposed. For example, Eitam, Kennedy and Higgins (2013) demonstrated that task motivation is increased when control over an effect can be clearly established by the participant. In that sense, decrease in the sense of control could directly impact the performance of human operators in system supervision associated with a 'diffusion of responsibility' (Caspar et al. 2017). With the development of automation, understanding and overcoming these difficulties remains a crucial challenge in the HCI domain.

\section{Toward the design of more acceptable system: the current approach}

Different solutions have already been investigated by the HCI community to design more acceptable and engaging interfaces. For example, it has been proposed to manipulate the level of system automation by sharing the authority between the automation and the human operator (for example, Men-Are-Better-At / Machines-Are-Better-At method, adaptive function allocation). As previously introduced, the manipulation of the level of physical and/or cognitive involvement of the human operator in the task has the potential to affect explicit sense of control (see Berberian et al. 2012). Such a method also has been proved to increase both performance and situation awareness. However, this method implies a modification of the level of automation. With the development of an autonomous system (see for illustration a self-driving car), maintaining a relevant feeling of control for the human operator engaged in purely supervisory control will become a critical issue (Hancock 
2014). Function allocation method remains limited in resolving such a concern. Moreover, as pointed out by Flemisch et al. (2011), in addition to control, authority, ability and responsibility are also modified according to the level of automation within the human-machine system.

More holistic approaches have been proposed to encompass the difficulties coming from the introduction of automated systems (Banks, Stanton, and Harvey 2013; Hoc 2001, Hoc, Young, and Blosseville 2009; Hutchins 1995). These frameworks highlight the importance of the information processing and the communication between human operators and automated systems. For instance, it has been proposed to design automation systems as chatty co-drivers providing continuous relevant feedback to the driver to improve human automation interaction (Eriksson and Stanton 2016; Stanton, Dunoyer, and Leatherland 2011). Such an approach follows Norman's recommendations about the "need to provide feedback about the state of the system in a normal, natural way, much in the same way that human participants in a joint problem-solving activity will discuss the issues among themselves" (Norman, 1990, p. 586; see also Christoffersen and Woods 2002; Dekker and Woods 2002; Klein et al. 2004). Recently, the concept of distributed situation awareness (DSA; Stanton, 2016) has been proposed as a guide to design such communication between agents. DSA proposed that agents within a system each hold their own situational awareness, which may be very different from (although compatible with) that of other agents. Whereas other frameworks promote sharing the same picture between different agents of the system, DSA argues that each agent should only be aware of the relevant information necessary for completing his/her role (for more detailed information about this concept see Salmon et al. 2009; Stanton 2016; Stanton et al. 2006). To support team working, DSA focuses on how to shape transactions between the agents, that is how to ensure that the right information is activated and passed to the right agent at the right time. Whereas promoting DSA has been proved to increase overall performance in teams (see, for example, Kitchin and Baber 2016), it remains unclear how to shape such transactions between human and system to preserve a sense of control. As an illustration, studies have demonstrated the benefit of prime messages while interacting with automation (e.g., Koo et al. 2014; Navarro, Mars, and Hoc 2007; Navarro et al. 2010). However, if priming appears as a relevant solution to decrease the system's opacity, it also brings several 
problems regarding the system's acceptability. Such information may help, but could also hurt the user's acceptability if too much, or inadequate, information is given at an inappropriate moment (Koo et al. 2014; Navarro et al. 2007). Such conflicting information could result in a degradation of the sense of control.

It is important at this point to highlight a significant difference between the concept examined in this paper and those examined in prior HCI research. In this paper, we do not focus on performance. Instead we offer a new perspective, complementary to those described above, which focuses on how people experience their own sense of personal agency when interacting with technology, and how this sense of agency could impact system acceptability. Particularly, we assume that the framework of agency could be used as a complementary approach by focusing on how the content and the timing of the information transfer to the human operator could maintain operator sense of control while promoting overall system performance.

\section{Agency: a complementary framework}

Laboratory studies have attempted to shed more light on the mechanisms underlying the experience of intentional causation and the sense of control of our own actions and empirical data in psychology (e.g., Aarts, Custers, and Wegner 2005; Moore, Wegner, and Haggard 2009), psychopathology (e.g., Franck et al. 2001; Frith, Blakemore, and Wolpert 2000) and neuroscience (e.g., Farrer et al. 2003; Tsakiris and Haggard 2005) have been accumulated. Interestingly, a variety of sources of information (e.g., one's own thoughts, interoceptive sensations, external feedback, etc.) could be involved in the authorship processing, and a multiple cues integration mechanism has been proposed (Moore et Fletcher 2012; Synofzik et al. 2009; Synofzik et al. 2013).

Notably, Wegner and colleagues has proposed the apparent mental causation theory which assumes that agency is experienced when we draw the inference that our thought has caused our action — whether or not this inference is correct (Wegner and Wheatley 1999). These authors indeed claim that an action is perceived as willed: 1) when the thought precedes the action at a proper interval (called the priority principle), 2) when the thought is compatible with the action (consistency 
principle), and 3) when the thought is the only apparent cause of the action (exclusivity principle). Following that theoretical proposition, Wegner, Sparrow, and Winerman (2004) reported that priming effects (i.e., providing predictive information of what will happen next) is a good way to influence or simulate prior thoughts, and therefore create a sense of agency even in the absence of any movement (see also Moore, Wegner, and Haggard 2009; Sato 2009). In their study, participants watched themselves in a mirror while another person behind them, hidden from their view, moved their hands forward on each side where participants' hands would normally appear, and performed a series of movements. When participants could hear instructions previewing the movements, they experienced a higher degree of agency for these movements. We assume that this priming effect could be used to improve communication between automation systems and operators and increase the feeling of control in a supervision context.

In this regard, one goal of the present study is to explore the relevance of the principles proposed by Wegner and colleagues in human machine interaction domain. Particularly, we propose to explore the benefit of prime messages regarding system intention while supervising an automated system. In a series of two experiments, we test whether providing information about what the system is about to do next leads to an increase in the level of user acceptability, concomitant with an increase in control and performance. Note here that our main concern is not about increasing human operator performance but about preserving the sense of control when interacting with a highly automated system. Two experiments have been performed to explore this question.

\section{Experiment 1: Link between system intention priming and system acceptability}

Improving acceptability of new technologies by human operators is an important area of concern to equipment suppliers (Horberry, Stevens, and Regan 2014). To be acceptable, new technologies must be reliable, efficient and useful. However, such qualities do not guarantee acceptability from human operators. As pointed by Shneiderman and Plaisant (2004), users strongly desire the sense that they are in charge of the system and that the system responds to their actions. In 
that sense, decrease in the sense of control when dealing with a highly automated system has the potential to seriously threaten this system acceptability.

In this first experiment, we aimed to explore how priming system intention can improve system acceptability. Participants had to perform an aircraft supervision task together with a secondary target-tracking task. To appraise the quality of the interactions with the automated system, we used a combination of objective measures with subjective ratings (Annett 2002). Effective control and performance were measured by reaction times in taking over the system when it required a nonoptimal decision (i.e., the autopilot decision would lead to a collision with a second obstacle). Ratings of user acceptability were also assessed for every experimental condition. Finally, a portable eyetracking system was used to monitor the way participants allocated visual attention resources during both tasks (i.e., supervision and tracking). This last measure provides additional information about the operator's performance and the smoothness of its interactions with the automated system.

\section{Methods}

\section{$\underline{\text { Participants }}$}

Twenty-four undergraduate students from Aix-Marseille University with normal or correctedto-normal vision participated in this experiment (mean age $=24.5 ; \mathrm{SD}=5.1 ; 15$ females). All participants were naive to the purposes of the study, and had no particular expertise in aircraft control.

\section{$\underline{\text { Material }}$}

This experiment was conducted using ONERA's airplane simulator (LabSim, ONERA, French Aerospace Lab, Salon de Provence). Participants were expected to perform two tasks in parallel: an aircraft supervision task and a tracking task (see Figure 1). This secondary task was used to increase the participant's mental workload (Young et al. 2015), and therefore make the supervision task harder. This situation is also more ecological since, in standard aeronautic situations, human operators usually have more than one screen or one action to supervise and often need to switch quickly and efficiently between various tasks. However, the ecological validity remains limited due to the poor familiarity of our participants with these supervision tasks and, as well, their relative simplicity. 


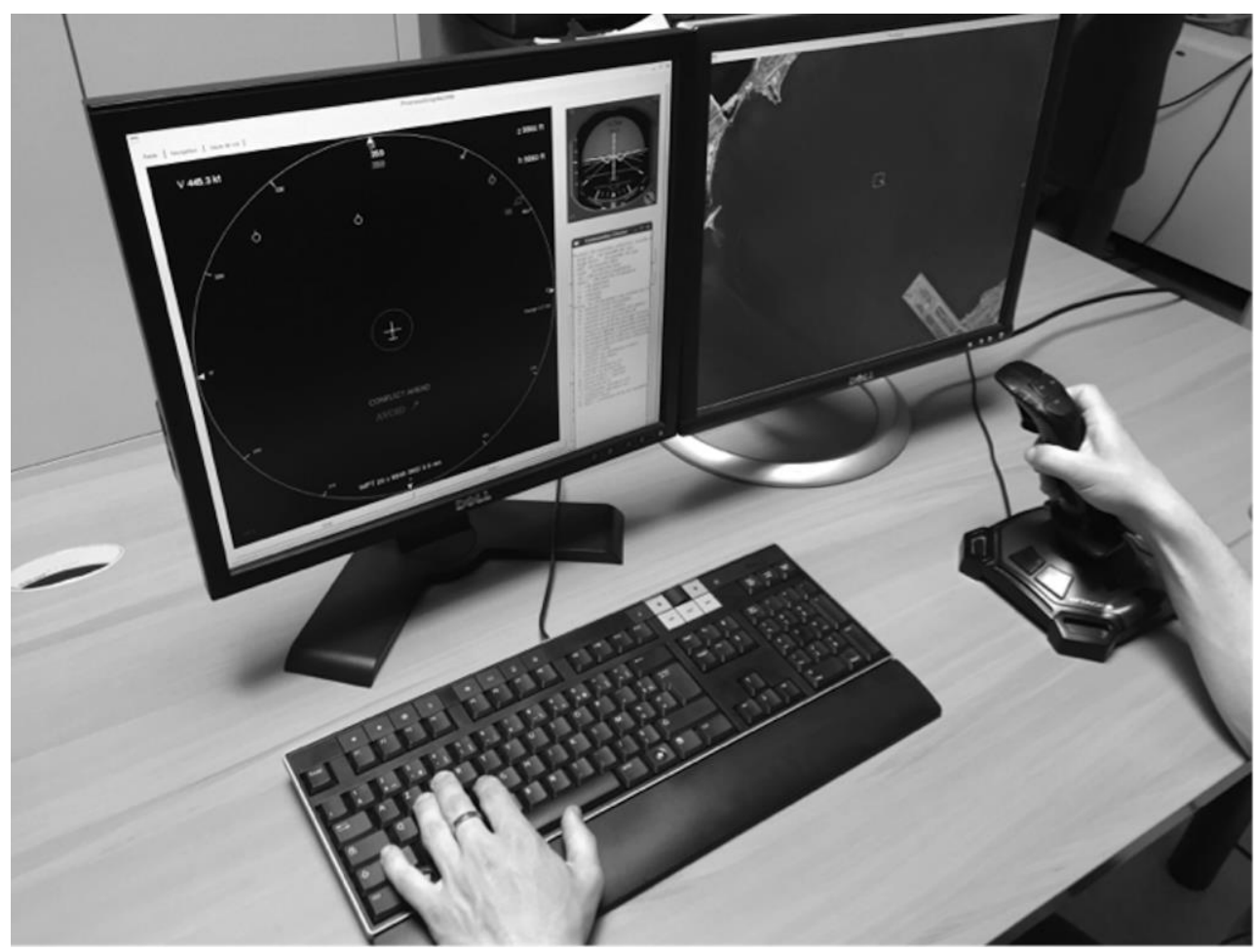

Figure 1. Schematic representation of the apparatus during the experiment. The Supervision task is displayed on the left screen and the Tracking task on the right screen.

\section{Supervisory task}

\section{Procedure}

The simulator was composed of a navigation display representing the aircraft in the horizontal plane together with surrounding traffic (see Figure 2). Participants had to supervise the progress of an aircraft on a predefined flight path, through two conditions: a 'temporal priming condition' and a 'directional priming condition'. At the beginning of each trial, participants were informed about the condition. After a 3-second delay, an obstacle (another aircraft) appeared on their path. A message 'CONFLICT AHEAD' appeared on the screen to warn the participant that this obstacle could penetrate the safety envelope of the plane if no change in its direction occurred. In both conditions, the autopilot system automatically detected and selected a new direction to avoid the potential conflict without any intervention of the participant. The two priming conditions were defined by the degree of information displayed by the autopilot to participants when a conflict was detected. In the 'temporal priming condition', when the autopilot selected a new direction, the message 'AVOID' appeared on the screen indicating that the plane was about to avoid the obstacle. In the 'directional priming 
condition', the message 'AVOID' appeared together with an arrow and a mark on the large white circle representing the angular indication. The arrow and the mark indicated the direction selected by the system before implementing this command. The 'temporal prime condition' was used to evaluate the effect of providing temporal information about the command to be executed. By adding angular indications in the 'directional prime condition', it was possible to test the effect of providing information about the subsequent action. Note that primes were always predictive of the action.

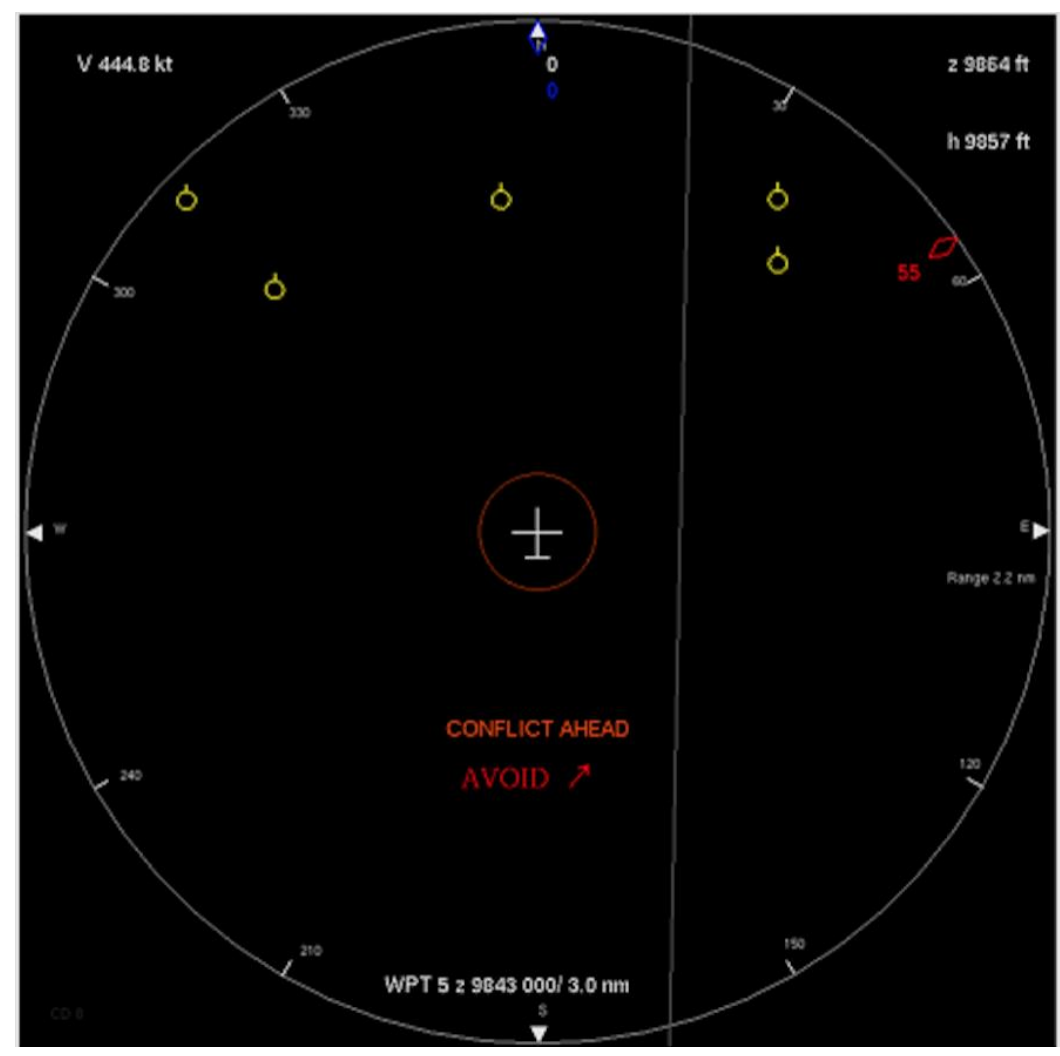

Figure 2. Experimental set up with the navigation display: the large white circle represents the angular indication. The smaller white circle surrounding the plane represents the aircraft safety envelope. Before implementing a new path, the message 'AVOID' appeared together with an arrow and a mark on the large white circle indicated the future direction selected by the system.

If the decision chosen by the autopilot was perceived as optimal, participants were instructed to let the autopilot control the aircraft and execute the command. Otherwise, participants had to press the 'e' key (for 'error') as quickly as possible. These situations were relatively rare during the experiment ( $8 \%$ of the trials) and they simulated a typical case in which a takeover had to be performed. These takeover situations always had the same structure: the autopilot selected a direction 
that prevented a collision with a first obstacle, but this direction led to a collision with another obstacle. Regardless of the condition and if a takeover was required, a green message 'CLEAR' plus a sound indicated to the participant the end of a trial. The inter-trial interval lasted for ten seconds.

The experiment was organised in continuous blocks during which the aircraft was supposed to follow a predefined trajectory. Each block lasted for about seven minutes. In each block, ten potential conflicts with the surrounding traffic were implemented. For each potential conflict, the autopilot system indicated that it detected an incoming obstacle and it selected automatically a new direction to avoid the conflict. Participants had to judge the autopilot decision and to press the 'e' key when they considered that the decision was inappropriate or not optimal. The nonoptimal autopilot decisions would lead to collision with a second obstacle. Failure to detect a nonoptimal decision led to a red circle surrounding the aircraft. If they correctly pressed the 'e' key, participants were told that their aircraft reduced its altitude to avoid collision and therefore, the red circle did not appear. There were five blocks in each experimental condition (i.e., in the 'temporal priming' and the 'directional priming' conditions) resulting in a total of 50 potential conflicts to supervise in each condition. Among these 100 potential conflicts, 60 were used as fillers ( 30 per condition). These filler trials were simple situations with few obstacles (one or three) leading systematically to a clear and unambiguous decision of the system. These simple conflicts were used to introduce some variability in the task. The 40 remaining potential conflicts were more complex, with three fixed obstacles and two moving aircrafts. Among these 40 potential conflicts ( 20 per condition), eight required pressing the 'e' key and taking over the autopilot's decision (four for each prime condition). Therefore, out of 100 conflicts, there were a total of eight takeover conflicts appearing in a pseudo-random order. The two constraints for the pseudo-randomisation were to avoid an error at the beginning of a block and to avoid two errors in a row. Participants were exposed to each condition alternately. Half of them began with the 'temporal priming' condition and the other half with the 'directional priming' condition. At the beginning of each block, the experimenter informed the participant about the type of blocks (s)he was about to perform. 
The time elapsed between the conflict detection signal (indicating the presence of an obstacle) and the 'e' key pressing was recorded (i.e., reaction time) to evaluate the performance of participants in these takeover situations.

\section{Tracking Task}

\section{Procedure}

This task was performed on a second screen, at the same time as the supervision task and was inspired by the tracking subtask from the Multi-Attribute Task Battery (MATB; Comstock and Arnegard 1992; Molloy and Parasuraman 1996). This 2D compensatory tracking task took place above a lake which was represented by a 'God's eye view' (Figure 3). Participants were instructed to keep the square cursor as close as possible to a moving target (a boat) by using a joystick. The color of the square cursor depended on its position relative to the target, in order to provide a visual feedback to the operator. This feedback was green when the cursor was on the target (i.e., when it covered at least $75 \%$ of the target's surface) and red otherwise. The target alternated between stationary position and movements. When the target moved, it was following a predefined straight trajectory. This second task was selected to be coherent with the supervision task and maintain the participant in an aeronautical framework. The two screens were positioned next to each other, so both could be monitored without changing posture. Participants were told that if a takeover in the supervision task was needed, this task became the priority even if the target moved outside the cursor.

During each block of the supervision task, 20 movements of the target were implemented in the tracking task. Each movement lasted about 8 s. The trajectory was random as well as the interval between two movements (i.e., stationary position). The participants' performance during the tracking task was evaluated by a time ratio corresponding to the time spent 'on the target' (i.e., when the cursor was green) over the 'total time'. 


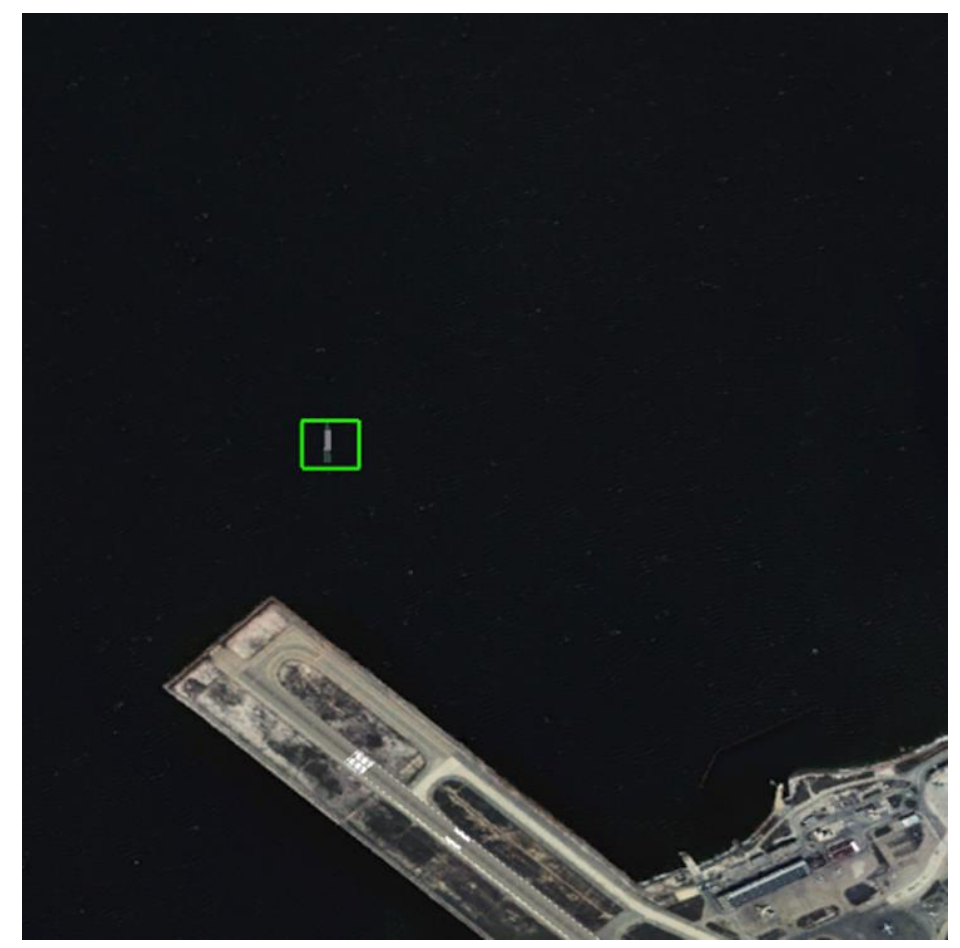

Figure 3. Representation of the target and the cursor. If the coverage is higher than $75 \%$ of the target's surface, the cursor appears in green otherwise it appears in red.

\section{$\underline{\text { Additional measures }}$}

Participants wore eye-tracking glasses (SensoMotoric Instruments $\odot$ Eye Tracking Glasses 2GW; Sampling rate: $120 \mathrm{~Hz}$ ) to record gaze direction and fixation time. These measures served to assess the allocation of visual attention on each screen (and therefore each task) as well as the number of visual/attentional switches between the two computer screens. The aim of these two measures was to evaluate the allocation of attentional resources in experimental conditions.

At the end of the last block for each condition (ninth block for temporal priming and tenth for directional priming or the opposite depending on the prime condition of the first block), the level of user acceptability of each automated system (i.e., the automated system with the temporal priming and the one with the directional priming) was assessed by asking participants to answer seven questions (see Appendix A) on a 7-point Likert-type scale $(1=$ totally disagree, $7=$ totally agree $)$. The questions were adapted from Verbene, Ham, and Midden's (2012) questionnaire and contain items related to 'trust dimension' (I found this system reliable; I trust this system), 'safety dimension' (This system 
increases my performance during the supervision task; Using this system increases the safety level) and perceived ease of use (It is difficult for me to understand the system's behaviour; Using this system does not require high attentional resources; Using this system is stressful). These dimensions are known to be fundamental for user acceptability (Ghazizadeh, Lee, and Ng Boyle 2011; Lee and Moray 1994; Parasuraman, Sheridan, and Wickens 2008; Venkatesh 2000). Answers to these questions were averaged to form a reliable measure of acceptability (Cronbach's alpha $=.87$ ). Higher scores reflect more acceptability of the automated system.

\section{Results}

The results concerning measures of response time in situations requiring a take-over and measures on the time spent on the tracking task are reported in Figure 4. Regarding the delay in pressing the 'e' key, there was a significant difference between the two experimental conditions $(t(23)$ $=2.23, p<0.05)$. Participants detected a system error sooner in the directional prime condition $(6.9$ sec. on average) than in the temporal prime condition ( $7.6 \mathrm{sec}$; Figure 4, left panel).

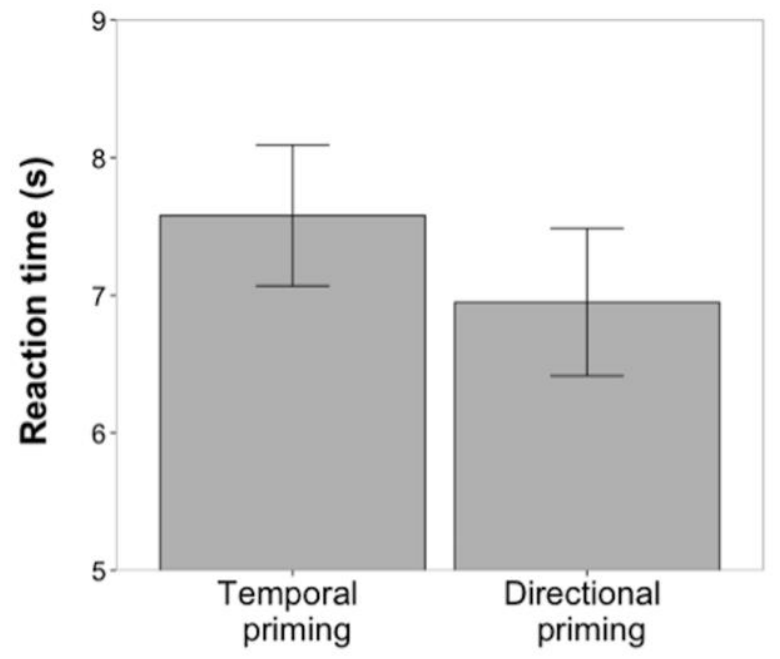

Levels of automation

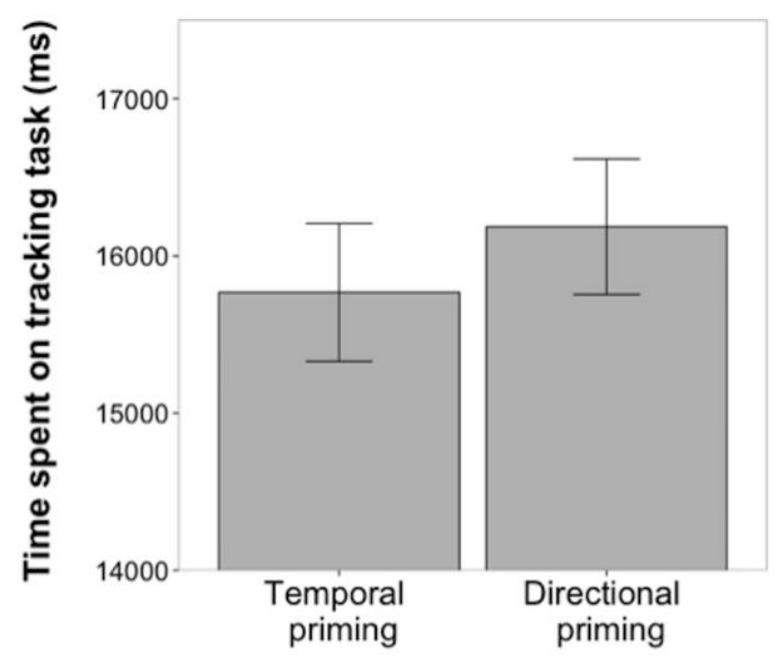

Levels of automation

Figure 4. Left: Mean response times to press the 'e' key in the two experimental conditions. Right: Mean time spent on the tracking task during a trial. Error bars represent standard errors of the mean.

Eye-tracking measures revealed that when information on the system's upcoming behaviour was provided, participants tended to produce fewer switches between the two tasks $\left(\operatorname{Mean}_{\text {temporal }}=11.9\right.$ and Mean $\left._{\text {directional }}=11.4 ; t(23)=1.8, p<0.08\right)$. This smaller number of task switches is concomitant 
with an increase in time spent on the tracking task (Figure 4, right panel). Participants spent more time on average paying attention to the tracking task during a trial in the directional prime condition (16186ms) compared to the temporal prime condition $(15769 \mathrm{~ms})(t(23)=2.44, p<0.05)$. However, this difference in time spent on the tracking task did not lead to an increase in performance. A paired $t$ test revealed that there was no significant difference in the time ratio spent on the target during the tracking task between the two experimental conditions $(t(23)=0.39, p>0.05)$. Participants spent $77.98 \%$ of the time on the target in the temporal prime condition and $77.73 \%$ of the time in the directional prime condition. This absence of difference in the two experimental conditions might be due to a ceiling effect, the task being too easy to really help discriminate performances in the two conditions.

As hypothesised, a paired $t$-test on the acceptability scale revealed that participants rated the automated system that provided information about the direction of the action more acceptable $(\mathrm{M}=$ $5.28, \mathrm{SD}=0.83)$ than the automated system that only provided temporal information $(\mathrm{M}=4.66, \mathrm{SD}=$ $0.99)(t(23)=2.46, p<0.05)$. Particularly, the first system is evaluated more positively through items related to 'trust dimension' (I found this system reliable; I trust this system), 'control dimension' (This system increases my performance during the supervision task; Using this system increases the safety level) and perceived ease of use (It is difficult for me to understand the system's behaviour; Using this system does not require high attentional resources; Using this system is stressful).

\section{Discussion}

Our results showed that providing additional direction information about the system's intentions led to: (1) an increase of the operator's level of user acceptability, (2) better performance in detecting the system's non-optimal decisions (i.e., shorter reaction times) and (3) a change in allocation of attentional resources. Critically, our results suggested an increase in system acceptability in presence of system intention priming. If we assume that such an increase results in the development of the sense of control, it could also be related to the presence of more information or attentional cueing in the case of priming conditions. Particularly, the use of spatial cues has been proved to facilitate reaction times to targets (see for illustration Posner 1978). Such an increase in performance 
could explain changes in the system acceptability. A second experiment is proposed to clarify the relation between system acceptability and sense of control.

\section{Experiment 2: System acceptability, sense of control and system priming intention: A matter of time}

Our first experiment demonstrated the benefit of prime messages regarding system acceptability and performance. However, it remained unclear how this priming impacts the sense of control and how this sense of control modulates the system acceptability. To explore these issues, this second experiment focuses on the impact of time on performance, system acceptability and sense of control. The question of timing appears to have an impact on the strength of the agency felt by the participant (Wegner and Wheatley 1999). To be optimal, the prior thoughts triggered by the primes should occur neither too far nor too close of an action (i.e., the priority principle). Particularly, Wegner and Wheatley (1999) showed a quadratic relation between the timing of the prime message and the sense of control.

In this context, this second study aimed to test if priming the automated system's intentions at different time intervals had similar effects on performance, sense of control and user acceptability. First, we expect to replicate the quadratic relation between priming temporality and sense of control in a more complex situation. Second, if priming system intention impacts system acceptability through the sense of control, we assume that system acceptability should present the same trend (i.e., a quadratic tendency), independent of the evolution of the performance. In contrast, if priming system intention impacts system acceptability through operator performance, or through the presence of additional information, a different trend should be observed at the acceptability level.

\section{Method}

\section{$\underline{\text { Participants }}$}

Sixteen participants with normal or corrected-to-normal vision participated in this experiment (mean age $=27.07 ; \mathrm{SD}=4.8 ; 7$ females). All participants were naive to the purposes of the study, and had no particular expertise in aircraft control. 


\section{Material}

As in the first experiment, participants were expected to perform two tasks in parallel: an aircraft supervision task and the Multi-Attribute Task Battery II (MATB; Santiago-Espada et al. 2011).

\section{Supervisory task}

$\underline{\text { Procedure }}$

The supervisory task was similar to the first experiment, but only the directional priming condition was performed. In this second experiment, we manipulated the moment when the prime message was presented. This prime message appeared either at $13 \mathrm{~s}, 7 \mathrm{~s}, 4 \mathrm{~s}$ or $1 \mathrm{~s}$ before the implementation of the new direction, defining the four experimental conditions.

As in the first experiment, if the decision chosen by the autopilot was perceived as optimal, participants were instructed to let the autopilot control the aircraft and execute the command. Otherwise, when they considered that the decision was inappropriate or not optimal, participants had to press the 'e' key (for 'error') as quickly as possible.

The experiment was organised in continuous blocks during which the aircraft followed a predefined trajectory. In each block, seven potential conflicts with the surrounding traffic were implemented. There were three blocks in each experimental condition (i.e., 13s, 7s, 4s, 1s conditions) resulting in a total of 21 potential conflicts to supervise per condition. Among these 84 potential conflicts (21 potential conflicts $* 4$ conditions), 12 required pressing the 'e' key to report a nonoptimal decision from the autopilot (three for each of the four conditions). Each block lasted about six minutes. Participants were exposed to each condition in a completely random order.

The time elapsed between the prime message (indicating the future direction) and the 'e' key press was recorded in order to evaluate the performance of participants in these critical situations.

\section{$\underline{\text { Multi-Attribute Task Battery II: }}$}

MATB II is a multi-tasking research platform designed to assess performance on four main, concurrent tasks (tracking, monitoring, resource management, and communications; see Figure 5). 
MATB II is an updated version of the original MATB (Comstock \& Arnegard 1992; Santiago-Espada et al. 2011). This task was performed on a second screen, at the same time as the supervision task. We did not use the tracking task.

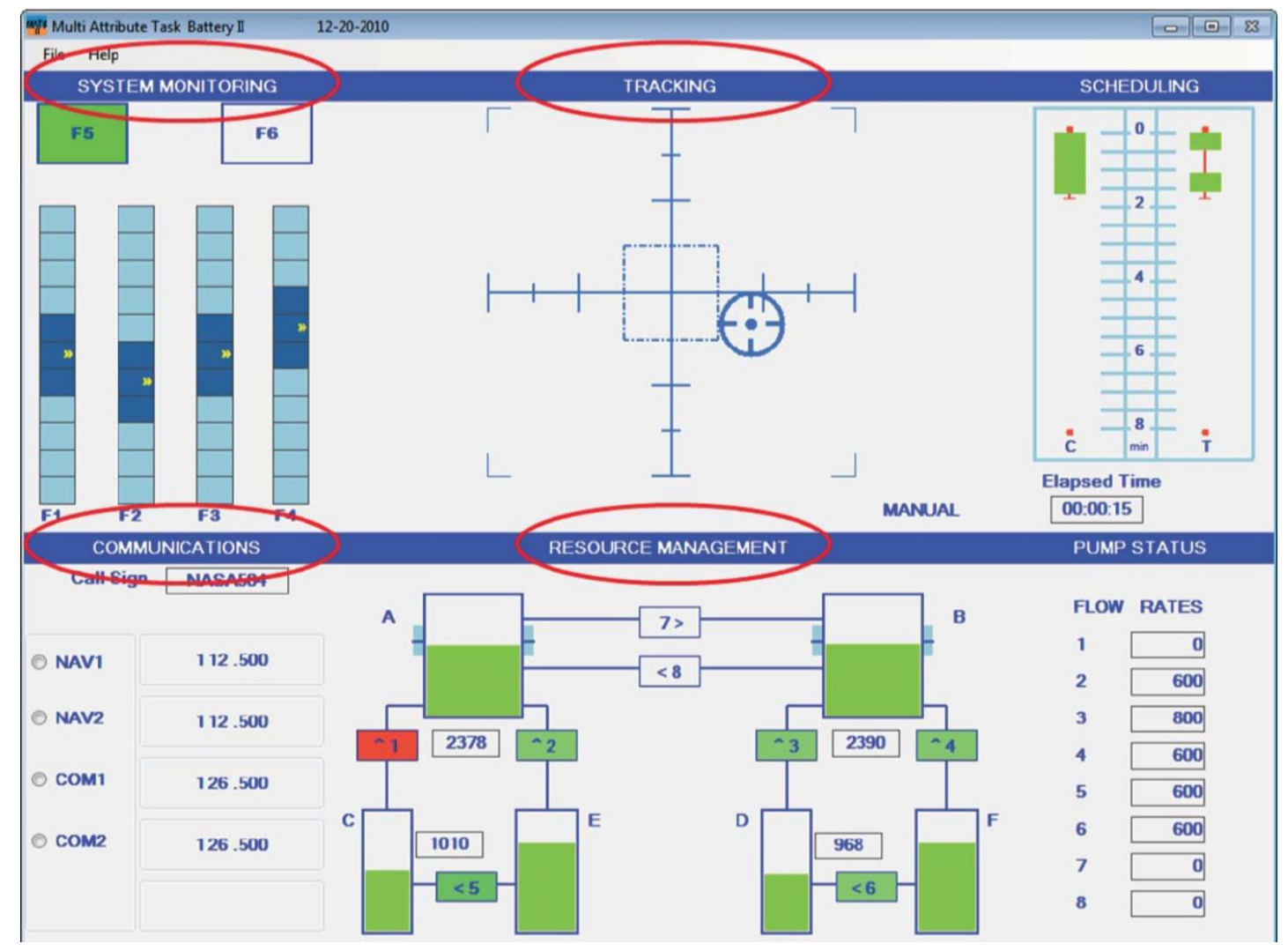

Figure 5. The tasks for the Multi-Attribute Task Battery II

\section{Procedure}

The monitoring task had two components: operators responded to red and green lights, and to scales that go out of range by registering either too high or too low. The resource management task represented fuel management aboard an aircraft. Operators maintained fuel in two tanks that continually deplete below target levels. Tanks are connected by pumps, which direct resource flow into or out of each of the tanks, and are controlled by the operator to regulate tank levels. Events in resource management are failures of interconnecting pumps. In each test trial, pumps failed once in randomised order, and were repaired automatically. The communication task simulated pilot interaction with air traffic controller requests. Operators heard command messages to change radio and 
frequency on one of four communications radios. The instructions were directed either to an 'other' ship or to the operator's own ship by using a callsign designated during training. Requests could be ignored unless the own sign was called.

\section{$\underline{\text { Additional measures }}$}

Three cameras tracked participants' eyes to evaluate the time spent on each task. The aim of this measure was to evaluate the allocation of attentional resources depending on the experimental condition. We hypothesised that priming system's intentions has a different impact on our measures of interest depending on the timing.

At the end of each block, participants were asked to evaluate their sense of control over the automated system and their acceptability. Sense of control was measured by a classic question in the agency literature (I felt myself in control of the conflict avoidance maneuver) on a 7-point Likert-type scale $(1=$ totally disagree, $7=$ totally agree $)$. Then, acceptability of the automated system from the supervision task was measured by the same questionnaire as the one for the first experiment (see Appendix A). Answers to these questions were averaged to form a reliable measure of acceptability $($ Cronbach's alpha $=.87)$. Higher scores reflect more acceptability of the automated system.

\section{Data Analysis}

For all three measures described in this second experiment, we were interested in knowing which trend best describes their relation with the delay between the prime message and the system's action. We focused on trend analysis because determining the best timing to prime system intentions was not our primary concern in this experiment. Then only the tendency of the relation was investigated hereafter. We tested both a linear and a quadratic contrast by using a bootstrapping sampling technique (Efron and Tibshirani 1993) with $\mathrm{n}=2000$. Bootstrap methods provide a robust way of testing hypotheses and computing confidence intervals without assuming normality (Wilcox, 2010, 2011; Xiong et al. 2008). Assuming normality could be problematic here because of our small sample size. Statistical significance is reached if zero is not included in the confidence interval. We only reported the most significant trend for each measure. 
$\underline{\text { Results: }}$

The results concerning measures of reaction time in situations requiring a take-over and measures on the time spent on the supervision task are reported in Figure 6. We performed a trend analysis. This analysis shows a significant linear trend $(\psi=7.75,95 \%$ CI $[6.71,8.80])$, indicating that as the delay between prime message and system's action decreased, reaction time decreased proportionately. We observed a similar linear trend for the time spent on supervision task $(\psi=2.94$, 95\% CI [1.70, 4.18]). Unsurprisingly, these results indicate that the reaction time and the time spent on supervision task are sensitive to the delay between prime message and system's action.

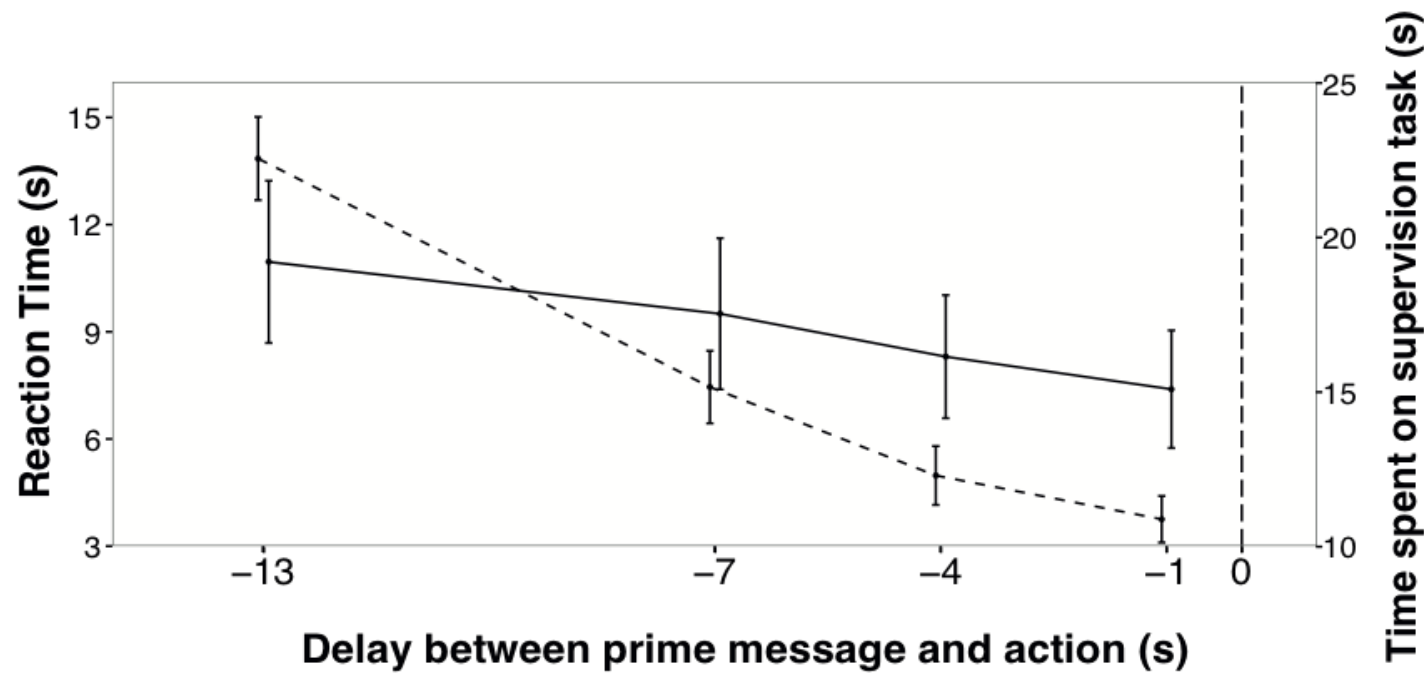

Figure 6. Mean response time to press the 'e' key (dashed line) and mean time spent on the supervision task during a trial (solid line) at each of the 4 delays. Errors bars are 95\% CIs.

Concerning the sense of control, we observed similarly to Wegner and Wheatley (1999) a quadratic polynomial effect $(\psi=-0.71,95 \%$ CI $[-1.25,-0.17])$. Compared with trials when prime messages were displayed $13 \mathrm{~s}$ or $1 \mathrm{~s}$, there was an increase of sense of control when the prime messages were displayed 7s or 4s before the system's action (see Figure 7). Interestingly, we observed a similar quadratic polynomial effect regarding evaluation of the user acceptability ( $\psi=-0.72,95 \%$ CI [-1.17, 0.28]). These results replicate the previous claim of Wegner and Wheatley (1999) that the timing of 
the prior thought in relation to the action is important to the sense of control. This claim can be extended to user acceptability in a supervision context.

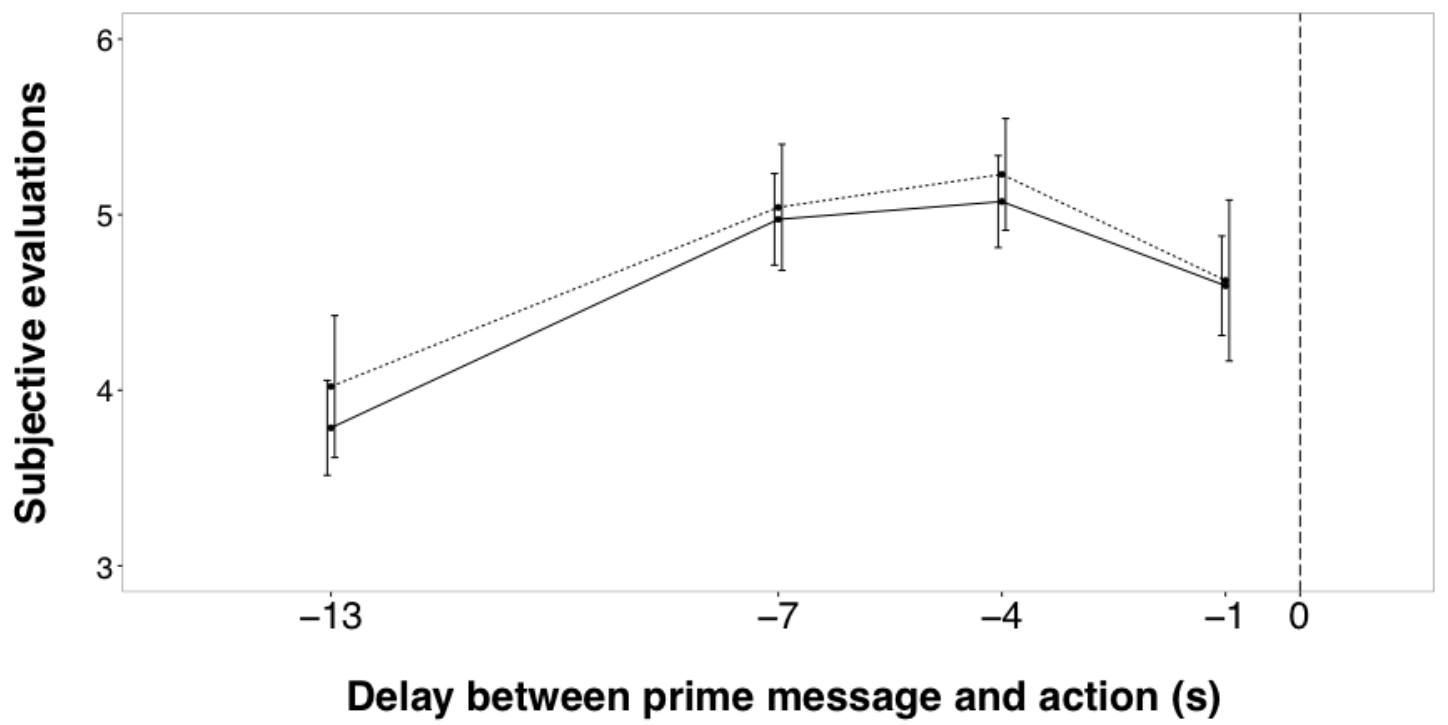

Figure 7. Mean values for the sense of control (dashed line) and the user acceptability (solid line) at each of the 4 delays. Errors bars are 95\% CIs.

\section{$\underline{\text { Discussion }}$}

Two main results were obtained in this second experiment. Our results showed that the delay between prime messages providing system's intentions and the system's actions: (1) had an impact on three major components of human-machine interaction (i.e., performance, operator's levels of control and acceptability), and that (2) this impact differs qualitatively regarding these three components (i.e., linear or quadratic trend). Particularly, both sense of control and system acceptability follow a quadratic trend whereas performance follows a linear trend.

In this second experiment, we clearly show that the simple presence of feedback is not enough to increase system acceptability. In contrast, system acceptability seems related to the development of the sense of control more than to the performance.

\section{General Discussion}

In the present study, we explore how the theoretical framework of agency might help 
determine the relevant information necessary for both an efficient transfer of control and an appropriate level of acceptability. Particularly, we tested whether providing information about what the system is about to do next can compensate for the decrease in the sense of control and the user acceptability traditionally observed when operators are confronted with high levels of automation. Our first experiment showed that providing additional direction information about the system's intentions impacts (1) system acceptability and (2) operator performance in case of system failure together with a change in allocation of attentional resources. Our second experiment indicates that the delay between prime messages providing system's intentions and the system's actions had a similar impact on both sense of control and system acceptability whereas this impact differs qualitatively regarding the performance (i.e., quadratic versus linear trend). Taken together, our results indicate that the principles proposed by this framework could help designers determine the parameters of the information (quantity, content, modality, timing, etc.) that should be primed by the automation to maintain a high level of sense of control in supervisory task and, as well, increase system acceptability.

\section{Prime and performance}

With respect to the relation between priming and operator performance, our results are in line with Norman's (1990) recommendations about the need to provide feedback on the state of the system and previous studies that have shown a benefit of prime messages in the HCI domain (e.g., Deroo, Hoc, and Mars 2012; Koo et al. 2014; Navarro, Mars, and Hoc 2007; Navarro et al. 2010). In this study, we go further in understanding the impact of such a prime message by assessing its benefit in a supervisory task, which is the main interaction mode for current technological systems, and frequently leads to an out-of-the-loop performance problem. The present data suggest that priming allows for a decrease in the negative impact of high level of automation. More specifically, providing information about the nature of the action that the system is about to perform increased the operator's ability to perceive the system's failures. This decrease in reaction time in presence of prime has been already observed in several studies. For example, Posner and colleagues (Posner 1978; Posner and Presti 1987; Posner, Snyder, and Davidson 1980) have shown that the use of spatial cues facilitates reaction times 
to targets. Our results replicated these findings. Our second experiment clarifies the impact of priming on reaction time. Those results showed a linear relationship between delay and reaction time to detect a non-optimal decision: longer delays led to longer reaction times. Recently, Gold et al. (2013) investigated the behaviour of drivers when a takeover was required due to an automation failure. An automated system managed core driving operations while drivers performed a secondary task. When the automation detected an unexpected event (i.e., a car stopped on the road), an alarm warned the driver that a takeover was required. It was found that drivers who received shorter takeover request times reacted more quickly. Our results are consistent with those of Gold et al. (2013) regarding reaction times. Priming system's intentions just before its action facilitates the creation of the intention-action-effect chain. This result is in line with Chambon and Haggard's (2012) findings that action priming affects the fluency of action selection processes and increases performance in reaction times.

\section{Priming and allocation of attention}

In addition to better reaction times, our results also show that providing the system's intentions could have an effect on the allocation of attention in a multi-task situation. While many pilots agree that modern aircraft are easier to fly, closer inspection suggests that their workload has shifted, rather than being reduced: pilots now have to carry out more supervisory tasks (Baxter, Besnard, and Riley 2007). Particularly, pilots can experience lack of knowledge on the current and future status of the autopilot (Rudisill 1995; Sarter and Woods 1995). This could lead pilots to spend more time trying to understand the aircraft's behaviour rather than focusing their efforts on the primary task of piloting the aircraft. Our results seem to indicate that making the system more transparent and more predictive could reduce the attentional load. Indeed, we found a reduced level of switching between the two tasks when spatial and temporal information was provided. This result is in line with the findings of Adler and Benbunan-Fich (2012) who showed that high frequency of task switching tends to degrade overall performance. We also found an increase in the time spent on the secondary task together with a decrease in the time spent on the supervision task. The average time spent on each area of interest is traditionally considered indicative of the difficulty to extract and interpret information from this area 
(Fitts, Jones, and Milton 1950; Jacob and Karn 2003). Therefore, providing information about the system's intentions seems to simplify the supervision task by making the task more automatic, and could lead to less cognitive effort in deciding whether a takeover is required, even if prime messages are additional content to process. This is consistent with the attentional resources approach of mental workload theory, as automatic processing releases attentional resources for other tasks, with a resulting decrease in mental workload (Young et al. 2015). Further studies are required to investigate if this decrease in attentional load could prevent operators from experiencing mental underload. As noted by Young and co-workers, there is now a strong consensus that mental underload can be detrimental to performance just as is mental overload (see also Desmond and Hoyes 1996; Hancock and Verwey 1997; Young and Stanton 2007). This underload could be a by-product of an over-trust on the autopilot. Studies have shown that what is required is an appropriate level of trust (Lee and See, 2004; Parasuraman, Molloy, and Singh, 1993). More recently, Payre, Cestac, and Delhomme (2015) showed that in a driving simulator task, participants with higher trust in automation had longer reaction times to recover a manual control; they suggested that appropriate training is required to overcome such problems. Although our participants evaluated the system more positively through items relating to the trust dimension, we must check that providing the system's intentions could not lead to an inappropriate level of trust or mental workload. In this context, an interesting avenue is the impact of the system's reliability on the observed results.

\section{Prime, sense of control and system acceptability}

If priming appears to impact performance and allocation of cognitive resources, our main concern here is of a different nature, namely the impact of priming information on the sense of control and the system's acceptability.

As mentioned previously, providing information about the system's upcoming behaviour is certainly not sufficient to increase the system's acceptability. Such information may help, but could also hurt, the operator's performance or user's acceptability if too much, or inadequate, information is given at an inappropriate moment. For instance, Koo et al. (2014) demonstrated that the benefits of prime messages depended on the nature and quantity of the displayed information. In a semi- 
autonomous driving task, they tested different messages that provided an explanation of the car's imminent autonomous action in advance (e.g., auto-braking function). They found that describing the car's future action ('how': 'the car is braking') and the reason for that action ('why': 'obstacle ahead') at the same time increased driving performance but decreased user acceptability. Similarly, Navarro et al. (2010) observed a dissociation between performance and acceptability. In a driving simulation task, they found that motor priming assistance (consisting of directional steering wheel vibrations) was more efficient compared to more traditional auditory (lateralised sound) warning devices. However, participants deemed classic auditory signal more acceptable than the motor priming system.

In this context, we proposed that using the theoretical framework of agency might help determine the relevant information necessary for both an efficient transfer of control and an appropriate level of acceptability. Our results show that providing the system's intentions actually increases both performance and user acceptability. Particularly, results on performance are corroborated by a more positive evaluation of this system through items relating to the control dimension and perceived ease of use. The nature of the task could explain the difference observed between our study and those previously cited (Koo et al. 2014; Navarro et al. 2010). Indeed, our study involved supervisory control whereas a manual control was required in the two other experiments. The benefit of providing priming information on performance and acceptability may therefore depend on the nature of the task. In a supervision context of a fully automatic system, the use of prime messages might be interpreted as communication rather than a form of intrusion. This result tends to indicate that to be fully efficient, interactions with automation must be conceived by designers in accord with the degree of automation they are creating.

The interplay of increasing automation between operators and automated systems tends to create a distance between operators and action outcomes, decreasing their feeling of control and the user acceptability of the system. Using prime messages allows the operators to follow the current goal of the automation and check if their own goals are similar to those of the system. Verberne et al. (2012a, 2012b) found that sharing goals between automation and drivers led to increased trustworthiness and user acceptability of the systems. They argued that people respond to technology in a social manner, in the same way they respond to other people (Reeves and Nass 1996). However, 
in a supervision context, the system carries out all actions without any human intervention. The human mainly monitors the system and intervenes if necessary (Endsley 1999). In that context, it is difficult for the operators to precisely follow the current goal of the system. This leads sometimes to 'automation surprises' (Sarter and Woods 1995; Sarter, Woods, and Billings 1997) occurring when automation behaves in ways that the operators do not expect. Recent aircraft accidents have been related to automation surprises, such as the Turkish Airlines TK1951 crash and the Air France AF447 crash, both in 2009 (Dutch Safety Board 2010; BEA 2012). Giving information about the system's intentions in the form of prime messages could be a solution to make the system a more collaborative agent.

Interestingly, our second experiment clarifies the link between sense of agency and system acceptability. Particularly, we observed an inverted U-curve describing the impact of the delay on the user's sense of control. Wegner and Wheatley (1999) showed a quadratic relation between the timing of the prime message and the sense of control. Although the timing delays used by Wegner and Wheatley $(-30 s,-5 s,-1 s,+1 s)$ are slightly different from ours $(-13 s,-7 s,-4 s,-1 s)$, both results suggest that prime messages should be displayed in a relevant temporal window to optimise the priority and congruency principles and to raise a correct sense of control. It is likely that this temporal window strongly depends on the task people do, and could differ between direct control, automated system supervision, and other tasks. Interestingly, we found that user acceptability followed the same quadratic pattern as the user's sense of agency. Although there was a tendency overall for participants to evaluate the system more acceptable when the delay between prime messages and actions decreases, there was a marked fluctuation in this evaluation depending on when the prime occurred. Participants evaluated the system as more acceptable when prime messages occurred neither too soon (-13 s) nor too late (-1 s). Therefore, warnings must be displayed but with a precise timing; otherwise, user acceptability might not be optimal. In other words, the proposed framework could be used as a complementary approach to the DSA concept by focusing on how the content and the timing of the information transfer to the human operator could maintain operator sense of control while promoting overall system performance. 


\section{Perspective and Conclusion}

Other issues remain to be addressed to complete our findings. A first avenue concerns the nature of the prime message. We indicate here that priming the system's intentions could improve human-machine interaction. Further studies are needed to evaluate the content of the prime message and the amount of information displayed in order to find optimal solutions to improve both performance and the sense of 'we-agency' of the operator toward the automated system (Obhi and Hall 2011; Pacherie 2012). A second avenue would be on the impact of the system's reliability on the proposed solution. System reliability is a major concern when considering human-automation interaction failure. Indeed, human operators generally interact with ultra-safe systems and very rare returns to manual control are expected. This reliability leads to the complacency phenomenon. In contrast, the number of system errors remains important (almost 10\%) in our study. How reliability modulates the impact of our prime message remains unclear. A third avenue involves the takeover situation. We propose in this study that priming the system's intentions could improve human machine interaction. However, we only considered here the performance of the human operator in terms of failure detection. To go further and firmly conclude that our priming solution could help keeping the human into the loop, we must assess how priming the system's intentions could increase participant's situation awareness and make their take-over behaviour more efficient.

In conclusion, although these results should be complemented in future research, the present study confirms that the psychological construct of the sense of agency can help in proposing design principles to improve human machine interaction when human operators are confronted with automated systems (Berberian et al. 2012; Le Goff et al. 2015; Limerick et al. 2014). This approach provides promising guidelines not only for improving the operator's performances but also the operator's sense of control and the system's acceptability. Automated systems which require operator monitoring or partial operator engagement are already widespread in transportation domain (aviation, car, train), and may soon become ubiquitous in advanced societies. Our results provide crucial information about how, and also when, such systems should issue signals to the operator to ensure optimal takeover control. For example, priming of drivers in automated vehicles could help regain control of the vehicle prior to the triggering of a warning (see Banks, Stanton, and Harvey 2014). As 
illustrate in transportation domain (autonomous car, Flight Managing System, Air Traffic Management system, Autonomous Unmanned Aerial System), improving communication between automation systems is a requirement to improve safety and performance when supervising highly automated systems. Many different domains as manufacturing (i.e., power plant automation systems), facility operations or financial domain (i.e., Automated Trading Systems) could also benefit from this cooperation improvement.

\section{References}

Aarts, Henk, Ruud Custers, and Daniel M. Wegner. 2005. "On the Inference of Personal Authorship: Enhancing Experienced Agency by Priming Effect Information." Consciousness and Cognition 14 (3): 439-58. doi:10.1016/j.concog.2004.11.001.

Adler, Rachel F., and Raquel Benbunan-Fich. 2012. "Juggling on a High Wire: Multitasking Effects on Performance." International Journal of Human-Computer Studies 70 (2): 156-68. doi:10.1016/j.ijhcs.2011.10.003.

Annett, John. 2002. “Subjective Rating Scales: Science or Art?” Ergonomics 45 (14): 966-87. doi:10.1080/00140130210166951.

Bandura, Albert. 1999. "A social cognitive theory of personality". In Handbook of personality, edited by L. Pervin \& O. John, 154-196. New York: Guilford Publications.

Bandura, Albert, Claudio Barbaranelli, Gian Vittorio Caprara, and Concetta Pastorelli. 1996. "Mechanisms of Moral Disengagement in the Exercise of Moral Agency." Journal of Personality and Social Psychology 71 (2): 364.

Banks, Victoria. A., Neville. A. Stanton, and Catherine Harvey. 2013. "What the Crash Dummies Don't Tell You: The Interaction between Driver and Automation in Emergency Situations." In 16th International IEEE Conference on Intelligent Transportation Systems (ITSC 2013), 2280-85. doi:10.1109/ITSC.2013.6728567.

Banks, Victoria. A., Neville. A. Stanton, and Catherine Harvey. 2014. "Sub-systems on the road to vehicle automation: Hands and feet free but not 'mind'free driving." Safety science, 62, 505-514.

Baron, Sheldon. 1988. "Pilot control". In Human factors in aviation, edited by E. L. Wiener and D. C. Nagel, 347-386. San Diego, CA: Academic Press.

Baxter, Gordon, Denis Besnard, and Dominic Riley. 2007. "Cognitive Mismatches in the Cockpit: Will They Ever Be a Thing of the Past?” Applied Ergonomics 38 (4): 41723. doi:10.1016/j.apergo.2007.01.005. 
BEA 2012. Final Report on the accident on 1st June 2009 to the Airbus A330-203 registered F-GZCP operated by Air France flight AF 447 Rio de Janeiro - Paris. Paris: Bureau d'Enquêtes et d'Analyses pour la sécurité de l'aviation civile, made available to the public on www.bea.aero.

Bednark, Jeffery G., and Elizabeth A. Franz. 2014. "Agency attribution: Event-related potentials and outcome monitoring." Experimental Brain Research 232.4: 1117-1126.

Berberian, Bruno, Jean-Christophe Sarrazin, Patrick Le Blaye, and Patrick Haggard. 2012. "Automation Technology and Sense of Control: A Window on Human Agency." PLoS One 7 (3). doi:10.1371/journal.pone.0034075.

Berberian, Bruno, Patrick Le Blaye, Christian Schulte, Nawfel Kinani, and Pern Ren Sim. 2013. "Data Transmission Latency and Sense of Control." In Engineering Psychology and Cognitive Ergonomics. Understanding Human Cognition, edited by Don Harris, 3-12. Lecture Notes in Computer Science 8019. Springer Berlin Heidelberg. http://link.springer.com/chapter/10.1007/978-3-642-39360-0_1.

Borg, Jana Schaich, Catherine Hynes, John Van Horn, Scott Grafton, and Walter SinnottArmstrong. 2006. "Consequences, Action, and Intention as Factors in Moral Judgments: An fMRI Investigation.” Journal of Cognitive Neuroscience 18 (5): 80317.

Bratman, Michael E. 2007. Structures of Agency: Essays. Oxford University Press.

Caspar, Emilie A., Julia F. Christensen, Axel Cleeremans, and Patrick Haggard. 2016. "Coercion Changes the Sense of Agency in the Human Brain." Current Biology. 26 (5): 585-592. doi:10.1016/j.cub.2015.12.067.

Caspar, Emilie A., Laurène Vuillaume, Pedro A. Magalhães De Saldanha da Gama, and Axel Cleeremans. 2017. "The Influence of (Dis)belief in Free Will on Immoral Behavior." Frontiers in Psychology 8. doi:10.3389/fpsyg.2017.00020.

Chambon, Valerian, and Patrick Haggard. 2012. "Sense of Control Depends on Fluency of Action Selection, Not Motor Performance." Cognition 125(3): 441-51. doi:10.1016/j.cognition.2012.07.011.

Christoffersen, Klaus, and David. D. Woods. 2002. "1. How to Make Automated Systems Team Players." In Advances in Human Performance and Cognitive Engineering Research, 2:1-12. Advances in Human Performance and Cognitive Engineering Research 2. Emerald Group Publishing Limited.

Comstock, J. Raymond, and Ruth J. Arnegard. 1992. "The Multi-Attribute Task Battery for Human Operator Workload and Strategic Behavior Research." Hampton, VA: National Aeronautics and Space Administration, Langley Research Center. http://ntrs.nasa.gov/search.jsp?R=19920007912.

Coyle, David, James Moore, Per Ola Kristensson, Paul Fletcher, and Alan Blackwell. 2012. "I Did That! Measuring Users' Experience of Agency in Their Own Actions." In Proceedings of the SIGCHI Conference on Human Factors in Computing Systems, 
2025-34. CHI '12. New York, NY: ACM. doi:10.1145/2207676.2208350.

Dekker, Sidney. W. A., and David. D. Woods. 2002. "MABA-MABA or Abracadabra? Progress on Human-Automation Co-Ordination." Cognition, Technology \& Work 4 (4): 240-44. doi:10.1007/s101110200022.

Deroo, Mathieu, Jean-Michel Hoc, and Franck Mars. 2012. "Influence of Risk Expectation on Haptically Cued Corrective Manoeuvres during near Lane Departure.” Ergonomics 55 (4): 465-75. doi:10.1080/00140139.2011.647094.

Desmond, Paula A., and Thomas W. Hoyes. 1996. "Workload Variation, Intrinsic Risk and Utility in a Simulated Air Traffic Control Task: Evidence for Compensatory Effects." Safety Science 22 (1): 87-101. doi:10.1016/0925-7535(96)00008-2.

Dutch Safety Board. 2010. Crashed during approach, Boeing 737-800, near Amsterdam Schiphol Airport, 25 February 2009. The Hague: Dutch Safety Board, made available to the public on www.safetyboard.nl.

Efron, Bradley, and Robert J. Tibshirani. 1993. An Introduction to the Bootstrap. New York, NY: Chapman \& Hall.

Eitam, Baruch, Patrick M. Kennedy, and E. Tory Higgins. 2013. "Motivation from control." Experimental brain research 229 (3): 475-484. doi:10.1007/s00221-012-3370-7

Endsley, Mica R. 1999. "Level of Automation Effects on Performance, Situation Awareness and Workload in a Dynamic Control Task." Ergonomics 42 (3): 462-92.

Eriksson, Alexander, and Neville A. Stanton. 2016. "The Chatty Co-Driver: A Linguistics Approach to Human-Automation-Interaction." In Contemporary ergonomics and human factors 2016: Proceedings of the international conference on ergonomics \& human factors.

Farrer, Chlöé, Nicolas Franck, Nicolas Georgieff, Chris. D Frith, Jean Decety, and Marc Jeannerod. 2003. "Modulating the Experience of Agency: A Positron Emission Tomography Study." NeuroImage 18 (2): 324-33. doi:10.1016/S10538119(02)00041-1.

Fitts, Paul M., Richard E. Jones, and John L. Milton. 1950. "Eye Movements of Aircraft Pilots during Instrument-Landing Approaches." Aeronautical Engineering Review 9 (2): $1-6$.

Flemisch, Frank, Matthias Heesen, Tobias Hesse, Johann Kelsch, Anna Schieben, and Johannes Beller. 2011. "Towards a Dynamic Balance between Humans and Automation: Authority, Ability, Responsibility and Control in Shared and Cooperative Control Situations." Cognition, Technology \& Work 14 (1): 3-18. doi:10.1007/s10111-011-0191-6.

Franck, Nicolas, Chlöé Farrer, Nicolas Georgieff, Michel Marie-Cardine, Jean Daléry, Thierry d'Amato, and Marc Jeannerod. 2001. "Defective Recognition of One's Own Actions in Patients With Schizophrenia." American Journal of Psychiatry 158 (3): 
454-59. doi:10.1176/appi.ajp.158.3.454.

Frith, Chris. D. 2014. "Action, agency and responsibility". Neuropsychologia 55: 137-142. doi: 10.1016/j.neuropsychologia.2013.09.007.

Frith, Chris D., Sarah-Jayne Blakemore, and Daniel M. Wolpert. 2000. "Explaining the symptoms of schizophrenia: abnormalities in the awareness of action." Brain Research Reviews 31(2): 357-363.

Ghazizadeh, Mahtab, John D. Lee, and Linda Ng Boyle. 2011. "Extending the Technology Acceptance Model to Assess Automation." Cognition, Technology \& Work 14 (1): 3949. doi:10.1007/s10111-011-0194-3.

Gold, Christian, Daniel Damböck, Lutz Lorenz, and Klaus Bengler. 2013. "“Take over!” How long does it take to get the driver back into the loop?" In Proceedings of the Human Factors and Ergonomics Society 57th Annual Meeting. Santa Monica, CA: Human Factors and Ergonomics Society. doi:10.1177/1541931213571433

Haggard, Patrick. 2017. "Sense of Agency in the Human Brain." Nature Reviews Neuroscience 18 (4): 196-207. doi:10.1038/nrn.2017.14.

Hancock, Peter. A. 2014. “Automation: How Much Is Too Much?” Ergonomics 57 (3): 44954. doi:10.1080/00140139.2013.816375.

Hancock, Peter. A., and Willem. B. Verwey. 1997. "Fatigue, Workload and Adaptive Driver Systems." Accident Analysis \& Prevention 29 (4): 495-506. doi:10.1016/S00014575(97)00029-8.

Hoc, Jean-Michel, Mark S. Young, and Jean-Marc Blosseville. 2009. "Cooperation between Drivers and Automation: Implications for Safety." Theoretical Issues in Ergonomics Science 10 (2): 135-60. doi:10.1080/14639220802368856.

Hoc, Jean-Michel. 2001. "Towards a Cognitive Approach to Human-machine Cooperation in Dynamic Situations." International Journal of Human-Computer Studies 54 (4): 50940. doi:10.1006/ijhc.2000.0454.

Horberry, Tim, Alan Stevens, and Michael A. Regan. 2014. Driver Acceptance of New Technology: Theory, Measurement and Optimisation. Ashgate Publishing.

Hutchins, Edwin. 1995. "How a Cockpit Remembers Its Speeds." Cognitive Science 19 (3): 265-88.

Jacob, Robert. J., and Keith S. Karn. 2003. Eye tracking in human-computer interaction and usability research: Ready to deliver the promises. In The mind's eye: Cognitive and applied aspects of eye movement research, edited by J. Hyönä, R. Radach, \& H. Deubel, 573-605. Amsterdam: Elsevier.

Kitchin, Joanne, and Chris Baber. 2016. "A comparison of shared and distributed situation awareness in teams through the use of agent-based modelling." Theoretical Issues in Ergonomics Science 17 (1): 8-41. 
Klein, Gary, David D. Woods, Jeffrey M. Bradshaw, Robert R. Hoffman, and Paul J. Feltovich. 2004. "Ten Challenges for Making Automation a 'Team Player' in Joint Human-Agent Activity." IEEE Intelligent Systems 19 (6): 91-95.

Koo, Jeamin, Jungsuk Kwac, Wendy Ju, Martin Steinert, Larry Leifer, and Clifford Nass. 2014. "Why Did My Car Just Do That? Explaining Semi-Autonomous Driving Actions to Improve Driver Understanding, Trust, and Performance." International Journal on Interactive Design and Manufacturing 9 (4): 269-275. doi:10.1007/s12008-014-0227-2.

Kühn, Simone, Ivan Nenchev, Patrick Haggard, Marcel Brass, Jürgen Gallinat, and Martin Voss. 2011. "Whodunnit? Electrophysiological correlates of agency judgements." PLoS One 6 (12): e28657. doi: 10.1371/journal.pone.0028657.

Lee, John D., and Katrina A. See. 2004. "Trust in Automation: Designing for Appropriate Reliance.” Human Factors 46 (1): 50-80. doi:10.1518/hfes.46.1.50_30392.

Lee, John D., and Neville Moray. 1994. "Trust, Self-Confidence, and Operators' Adaptation to Automation." International Journal of Human-Computer Studies 40 (1): 153-84. doi:10.1006/ijhc.1994.1007.

Le Goff, Kevin, Arnaud Rey, and Bruno Berberian. 2015. "Toward a Model for Effective Human-Automation Interaction: The Mediated Agency." International Conference on Digital Human Modeling and Applications in Health, Safety, Ergonomics and Risk Management. Springer International Publishing.

Li, Peng, Chunhui Han, Yi Lei, Clay B. Holroyd, and Hong Li. 2011. "Responsibility modulates neural mechanisms of outcome processing: an ERP study." Psychophysiology 48 (8): 1129-1133. doi: 10.1111/j.1469-8986.2011.01182.x.

Li, Peng, Shiwei Jia, Tingyong Feng, Qiang Liu, Tao Suo, and Hong Li. 2010. "The influence of the diffusion of responsibility effect on outcome evaluations: Electrophysiological evidence from an ERP study." Neuroimage 52 (4): 1727-1733. doi:10.1016/j.neuroimage.2010.04.275.

Limerick, Hannah, David Coyle, and James W. Moore. 2014. "The Experience of Agency in Human-Computer Interactions: A Review." Frontiers in Human Neuroscience 8. doi:10.3389/fnhum.2014.00643.

Limerick, Hannah, James W. Moore, and David Coyle. 2015. "Empirical Evidence for a Diminished Sense of Agency in Speech Interfaces." In Proceedings of the 33rd Annual ACM Conference on Human Factors in Computing Systems, 3967-70. ACM Press. doi:10.1145/2702123.2702379.

McEneaney, John E. 2009. "Agency Attribution in Human-Computer Interaction." In Engineering Psychology and Cognitive Ergonomics, edited by Don Harris, 81-90. Lecture Notes in Computer Science 5639. Springer Berlin Heidelberg. http://link.springer.com/chapter/10.1007/978-3-642-02728-4_9. 
McEneaney, John E. 2013. “Agency Effects in Human-Computer Interaction.” International Journal of Human-Computer Interaction 29 (12): 798-813. doi:10.1080/10447318.2013.777826.

Molloy, Robert, and Raja Parasuraman. 1996. "Monitoring an Automated System for a Single Failure: Vigilance and Task Complexity Effects." Human Factors 38 (2): 311-22. doi:10.1177/001872089606380211.

Moore, James W., and P. C. Fletcher. 2012. "Sense of Agency in Health and Disease: A Review of Cue Integration Approaches." Consciousness and Cognition 21 (1): 59-68. doi:10.1016/j.concog.2011.08.010.

Moore, James W., Daniel M. Wegner, and Patrick Haggard. 2009. "Modulating the Sense of Agency with External Cues." Consciousness and Cognition 18 (4): 1056-64. doi:10.1016/j.concog.2009.05.004.

Moretto, Giovanna., Eamonn Walsh, and Patrick Haggard. 2011. "Experience of Agency and Sense of Responsibility." Consciousness and Cognition, 20 (4): 1847-1854. doi:10.1016/j.concog.2011.08.014.

Navarro, Jordan, Franck Mars, and Jean-Michel Hoc. 2007. "Lateral Control Assistance for Car Drivers: A Comparison of Motor Priming and Warning Systems." Human Factors 49 (5): 950-60.

Navarro, Jordan, Franck Mars, Jean-François Forzy, Myriam El-Jaafari, and Jean-Michel Hoc. 2010. "Objective and Subjective Evaluation of Motor Priming and Warning Systems Applied to Lateral Control Assistance." Accident Analysis \& Prevention 42 (3): 904-12. doi:10.1016/j.aap.2009.07.008.

Norman, Donald. 1990. "The 'Problem' with Automation: Inappropriate Feedback and Interaction, Not 'Over-Automation."' Philosophical Transactions of the Royal Society of London. B, Biological Sciences 327 (1241): 585-93. doi:10.1098/rstb.1990.0101.

Obhi, Sukhvinder S., and Preston Hall. 2011. "Sense of Agency in Joint Action: Influence of Human and Computer Co-Actors." Experimental Brain Research 211 (3-4): 663-70. doi:10.1007/s00221-011-2662-7.

Pacherie, Elisabeth. 2008. "The Phenomenology of Action: A Conceptual Framework." Cognition 107 (1): 179-217.

Pacherie, Elisabeth. 2012. "The Phenomenology of Joint Action: Self-Agency vs. JointAgency." In Joint Attention: New Developments, edited by Axel Seemann, 343-389. Cambridge, MA: MIT Press.

Parasuraman, Raja, Robert Molloy, and Indramani L. Singh. 1993. "Performance Consequences of Automation-Induced 'Complacency.", The International Journal of Aviation Psychology 3 (1): 1-23. doi:10.1207/s15327108ijap0301 1.

Parasuraman, Raja, Thomas B. Sheridan, and Christopher D. Wickens. 2008. "Situation Awareness, Mental Workload, and Trust in Automation: Viable, Empirically 
Supported Cognitive Engineering Constructs." Journal of Cognitive Engineering and Decision Making 2 (2): 140-60. doi:10.1518/155534308X284417.

Posner, Michael I. 1978. Chronometric explorations of mind. Hillsdale, NJ: Lawrence Erlbaum.

Posner, Michael I., Charles R. Snyder, and Brian J. Davidson. 1980. "Attention and the detection of signals." Journal of experimental psychology: General 109 (2): 160.

Posner Michael I., and David E. Presti. 1987. "Selective attention and cognitive control." Trends in Neurosciences 10 (1): 13-17.

Payre, William, Julien Cestac, and Patricia Delhomme. 2015. "Fully Automated Driving: Impact of Trust and Practice on Manual Control Recovery." Human Factors 58 (2): 229-241. doi:10.1177/0018720815612319.

Reeves, Byron, and Clifford Nass. 1996. The Media Equation: How People Treat Computers, Television, and New Media like Real People and Places. Vol. xiv. New York, NY, US: Cambridge University Press.

Rudisill, Marianne. 1995. "Line pilots' attitudes about and experience with flight deck automation: Results of an international survey and proposed guidelines." In Proceedings of the 8th International Symposium on Aviation Psychology, edited by R. S. Jensen and L. A. Rakovan, 288-293. Columbus, OH: The Ohio State University.

Salmon, Paul. M., Neville A. Stanton, Guy H. Walker, Daniel Jenkins, Darshna Ladva, Laura Rafferty and Mark Young. 2009. "Measuring Situation Awareness in complex systems: Comparison of measures study." International Journal of Industrial Ergonomics 39(3): 490-500.

San Martín, René. 2012. "Event-Related Potential Studies of Outcome Processing and Feedback-Guided Learning." Frontiers in Human Neuroscience 6. doi:10.3389/fnhum.2012.00304.

Santiago-Espada, Yamira, Robert Myer, Kara Latorella, and James Comstock. 2011. "The Multi-Attribute Task Battery (MATB-II)." Software for Human Performance and Workload Research: A User's Guide. NASA/TM-2011-217164.

Sarter, Nadine B., and David D. Woods. 1995. "How in the World Did We Ever Get into That Mode? Mode Error and Awareness in Supervisory Control." Human Factors 37 (1): 5-19. doi:10.1518/001872095779049516.

Sarter, Nadine B., David D. Woods, and Charles E. Billings. 1997. "Automation Surprises." Handbook of Human Factors and Ergonomics 2: 1926-43.

Sato, Atsushi. 2009. "Both Motor Prediction and Conceptual Congruency between Preview and Action-Effect Contribute to Explicit Judgment of Agency." Cognition 110 (1): 74-83. doi:10.1016/j.cognition.2008.10.011.

Sheridan, Thomas B., and William L. Verplank. 1978. "Human and Computer Control of 
Undersea Teleoperators." Technical report for the Office of Naval Research. Cambridge, MA.

Shneiderman, Ben, and Catherine Plaisant. 2004. Designing the User Interface: Strategies for Effective Human-Computer Interaction. Pearson Addison-Wesley. Reading, MA.

Stanton, Neville A. 2016. "Distributed situation awareness." Theoretical Issues in Ergonomics Science 17 (1): 1-7. doi: 10.1080/1463922X.2015.1106615.

Stanton, Neville A., Alain Dunoyer, and Adam Leatherland. 2011. "Detection of new in-path targets by drivers using Stop \& Go Adaptive Cruise Control." Applied ergonomics 42 (4): 592-601.

Synofzik, Matthis, Gottfried Vosgerau, and Axel Lindner. 2009. "Me or Not Me - An Optimal Integration of Agency Cues?" Consciousness and Cognition 18 (4): 1065-68. doi:10.1016/j.concog.2009.07.007.

Synofzik, Matthis, Gottfried Vosgerau, and Martin Voss. 2013. "The experience of agency: an interplay between prediction and postdiction." Frontiers in psychology 4. doi: 10.3389/fpsyg.2013.00127.

Tsakiris, Manos, and Patrick Haggard. 2005. "Experimenting with the Acting Self." Cognitive Neuropsychology 22 (3-4): 387-407. doi:10.1080/02643290442000158.

Timm, Jana, Iria SanMiguel, Julian Keil, Erich Schröger, \& Marc Schönwiesner. 2014. "Motor intention determines sensory attenuation of brain responses to self-initiated sounds." Journal of cognitive neuroscience, 26 (7): 1481-1489. doi: 10.1162/jocn_a_00552.

Venkatesh, Viswanath. 2000. "Determinants of Perceived Ease of Use: Integrating Control, Intrinsic Motivation, and Emotion into the Technology Acceptance Model." Information Systems Research 11 (4): 342-65. doi:10.1287/isre.11.4.342.11872.

Verberne, Frank, Jaap Ham, and Cees Midden. 2012. "Trust in Smart Systems: Sharing Driving Goals and Giving Information to Increase Trustworthiness and Acceptance of Smart Systems in Cars." Human Factors 54 (5): 799-810. doi:10.1177/0018720812443825.

Verberne, Frank, Jaap Ham, and Cees Midden. 2012. "Trusting Automation Technology for Safer Roads: The Effect of Shared Driving Goals.” Persuasive Technology, 57.

Wegner, Daniel M., and Thalia Wheatley. 1999. "Apparent Mental Causation: Sources of the Experience of Will." American Psychologist 54 (7): 480-92. doi:10.1037/0003066X.54.7.480.

Wegner, Daniel M., Betsy Sparrow, and Lea Winerman. 2004. "Vicarious Agency: Experiencing Control Over the Movements of Others." Journal of Personality and Social Psychology 86 (6): 838-48. doi:10.1037/0022-3514.86.6.838.

Wilcox, Rand. 2010 Fundamentals of modern statistical methods: Substantially improving 
power and accuracy. Springer Science \& Business Media.

Wilcox, Rand. 2011. Modern statistics for the social and behavioral sciences: A practical introduction. CRC press.

Young, Mark S., Karel A. Brookhuis, Christopher D. Wickens, and Peter A. Hancock. 2015. "State of Science: Mental Workload in Ergonomics." Ergonomics 58 (1): 1-17. doi:10.1080/00140139.2014.956151.

Young, Mark. S., and Neville. A. Stanton. 2007. "What's Skill Got to Do with It? Vehicle Automation and Driver Mental Workload." Ergonomics 50 (8): 1324-39. doi:10.1080/00140130701318855.

Xiong, Huimin, Linda Ng Boyle, Jane Moeckli, Benjamin R. Dow, and Timothy L. Brown. 2012. "Use patterns among early adopters of adaptive cruise control." Human factors 54 (5): 722-733. doi: 10.1177/0018720811434512. 
Appendix A

Listed below are the items from the questionnaire used to measure the user acceptability of automation.

1. I found this system reliable

2. I trust this system

3. This system increased my performance during the supervision task

4. This system increases the safety level

5. It is difficult for me to understand the system's behavior

6. Using this system does not require high attentional resources

7. Using this system is stressful 